\title{
CIDADE-CLIMA E HIGIENE: APONTAMENTOS ACERCA DA TUBERCULOSE EM GUARAPUAVA DE 1927 A 1932
}

\author{
CITY CLIMATE AND HYGIENE: NOTES ABOUT THE TUBERCULOSIS IN \\ GUARAPUAVA FROM 1927 TO 1932
}

\begin{abstract}
Cláudia Maris Tullio | Lattes | claudiatullio31@yahoo.com.br Universidade Estadual do Centro-Oeste do Paraná
\end{abstract}

Micheli Rosa | Lattes | michelly.hist@gmail.com Universidade Estadual do Centro-Oeste do Paraná

\begin{abstract}
Resumo: A sociedade brasileira da década de 1920 a 1930 é permeada por muitos discursos que refletem o cotidiano, entre eles o discurso sobre os doentes. Desta maneira, a presente pesquisa utiliza-se da interdisciplinaridade entre História e Linguística para compreender a tuberculose em Guarapuava. A metodologia empregada parte do modelo Tridimensional de análise do discurso proposta por Norman Fairclough (2001). Sendo assim, o objetivo é analisar os tuberculosos a partir dos relatórios médicos do Hospital São Vicente de Paulo e entender como a doença é representada, bem como quais são as práticas de prevenção da doença no Brasil, especificamente na cidade, neste respectivo período.
\end{abstract}

Palavras-chave: Saúde; Profilaxia; Análise do discurso; Tísicos.

\begin{abstract}
The Brazilian society of decades, from 1920 to 1930, is surrounded by many speeches that talk about the daily, as the speech about sick people. Thus, this research took into account the interdisciplinary between History and Linguistics to understand the tuberculosis in Guarapuava. The methodology applied on this study is based on the three-dimensional speech analyses, by Norman Fairclough (2001). Therefore, the goals of this study are to analyze people who had tuberculosis, based on the medical reports of São Vicente de Paulo Hospital, in order to understand how this disease is represented, and what are the practices of prevention of tuberculosis in Brazil, specifically in the city, during that period of time.
\end{abstract}

Key words: Health; Prophylaxis; Discourse Analysis; Hectic. 


\section{Introdução}

A tuberculose é conhecida desde a antiguidade. Como aponta Bertolli Filho (2001, p. 30), é "uma das maiores ceifadoras de populações, pois, apesar da resistência humana ao bacilo, o 'mal consuntivo' mantém-se em estado endêmico através de gerações, comprometendo assim sucessivas sociedades". Nota-se que no final do 'Século das Luzes', os médicos ainda se utilizavam dos modelos terapêuticos da Antiguidade para tratar a doença, como a climatoterapia. Mesmo com passagem do século XVIII, percebe-se que esse tipo de tratamento era recurso muito utilizado pelos médicos para curar os tuberculosos, até mesmo pela falta de medicamentos, sendo que esta forma de tratar os doentes do peito estará presente até meados do século $\mathrm{XX}$, onde podemos perceber formas de tratamento mais eficazes contra a tuberculose.

Observa-se, ao longo da história, que vários pesquisadores empenharam esforços para identificar o micróbio responsável pela doença, entretanto o pioneiro na identificação foi o alemão Robert Koch. Sabe-se que em 1882 "o bacteriologista buscou aproximar a medicina laboratorial das práticas higienistas, sugerindo providências limitadoras da disseminação da doença consuntiva no contexto social” (BERTOLLI FILHO, 2001, p. 39).

No que tange à representação do doente do peito, verifica-se que foi construída uma noção de que portar a tuberculose no final do século XVIII era uma forma de distinção, de sensibilidade. Os textos literários mostravam a doença como um "dote" de uma parcela da elite, como se estivesse vinculada à sensibilidade e genialidade. A respeito da questão de que o culto à tuberculose era uma invenção dos poetas românticos, Sontag (1984, p. 41) comenta:

Todas as evidências indicam que o culto da tuberculose não era simplesmente uma invenção de poetas românticos e libretistas de ópera, mas uma atitude generalizada, e que a pessoa que estava morrendo (jovem) de tuberculose era vista como uma personalidade romântica.

A mudança ocorre no início do século $\mathrm{XX}$, pois surgem novos posicionamentos sociais e sanitários que negaram a boemia e a tuberculose como imagem da camada culta, ligando a consunção como moléstia das camadas pobres e marginalizadas. Desta forma, percebe-se que "na virada do século XX, [a tuberculose] passou a ser considerada um mal social e sua coerência encontra-se, desde então, associada às condições de vida” (SOARES, 1994, p. 127). 
A pesquisa abarca esse contexto, sendo que a proposta gira em torno de um estudo interdisciplinar entre a História e a Linguística. Esta no campo da Análise do Discurso, especificamente a Análise de Discurso Crítica de Norman Fairclough - Discurso e mudança social - que apresenta o modelo tridimensional de análise de discurso. Aquela se situa no campo da história das doenças. Esse campo de estudos está profundamente ligado ao contexto social, afinal as enfermidades sinalizam as crenças e os modos de tratamento por parte da esfera política e social.

O objetivo central deste artigo é, por meio das três dimensões do discurso (texto, prática discursiva e prática social), analisar como a tuberculose é representada nos relatórios do Hospital São Vicente de Paulo, pois, através dos respectivos documentos históricos, podemos "ler" a cidade, os seus discursos, seus símbolos, seu ritmo etc. Compreende-se que em torno da representação da doença estará presente a questão higiênica e a climatoterapia. Com relação à higiene em Guarapuava, o livro O Coração do Paraná, de Eurico Branco Ribeiro (1929), médico guarapuavano, contribui para pensarmos os problemas enfrentados pela cidade.

\section{Questões da Saúde Pública no Brasil: alguns apontamentos}

A partir da segunda parte, podemos perceber questões da saúde pública no Brasil e como ocorreu a intervenção do estado na Primeira República, especialmente no período do Governo Vargas, abordando como se deram as práticas de tratamento da tuberculose em nível nacional, comparando-as com as adotadas em Guarapuava/PR.

No começo do regime republicano, Bertolli Filho (2001) aponta que a saúde pública foi um dos setores que a administração governamental considerava que deveria interferir mais. Entretanto a intervenção higiênica se concentrou nos espaços urbanos. Além disso também houve a necessidade de dinamizar a circulação de homens e mercadorias, pois as enfermidades feriam o corpo social. Outra questão discutida pelo autor é que o então Governo Federal, na Primeira República, tentou conter o avanço das endemias e epidemias, visto que ameaçavam o cotidiano da população, liberando verbas e servidores para combater as várias doenças que assolavam as metrópoles, como também o interior do país.

No entanto observa-se que na Primeira República, o governo não tinha programas ou projetos de combate à tuberculose. Diferentemente das outras enfermidades, a tuberculose para Bertolli Filho, (2001, p. 61) "não contou com as atenções e os recursos oficiais, fazendo com que a sociedade assumisse as tarefas de criação e de patrocínio das ins- 
tituições que tinham o objetivo de prevenir o contágio e amparar os tuberculosos pobres”.

O desinteresse do governo pela tuberculose foi quebrado em 1907, momento em que foi aprovada a lei que obrigava a notificação de casos de tuberculose, proposta por Oswaldo Cruz. Entretanto, a proposta cruziana não obteve apoio dos políticos, haja vista que as cenas que marcaram a Revolta da Vacina deixaram impressionados os governantes, que rejeitaram o projeto de Oswaldo Cruz.

A criação da Liga Paulista de combate à Tuberculose em São Paulo, serviu como modelo para os outros Estados, "no Brasil, Ligas e Estado conduziram a política de controle da Tuberculose: coube às primeiras a construção de sanatórios e dispensários e ao poder público, inicialmente, a profilaxia, pela educação catequizante" (VIANNA; ELIAS, 2007, p. 1296). Percebe-se que, mesmo com a dificuldade de manter a Liga Paulista Contra a Tuberculose, esta iniciativa contribuiu como modelo para as outras campanhas estaduais que tinham como foco a tuberculose. Para Antunes, os sanatórios para tuberculosos são "um advento do século XX e perduraram até os anos 1960, quando começaram a ser superados, como concepção terapêutica e de controle da doença, pela difusão dos tratamentos ambulatoriais" (ANTUNES et al. 2000, p. 371).

A partir da década de 1920, observam-se cobranças mais intensas dos poderes públicos no combate à tuberculose, mas é notável a ausência oficial na luta contra a doença. Já em 1930, sob uma crise econômica houve a ruptura da oligarquia paulista e mineira em relação à tomada de decisões nacionais, em virtude da entrada de Getúlio Vargas no comando federal ter selado o encerramento de um período em que o Estado buscou amoldar-se à tradição liberal europeia e aos princípios federalistas. Em continuidade, "os 'revolucionários' de 30 orientaram seus projetos no sentido da centralização dos canais decisórios e na ostensiva intervenção governamental no funcionamento da sociedade" (BERTOLLI FILHO, 2001, p. 68).

Com a criação do Ministério da Educação e Saúde Pública (em novembro de 1930), percebe-se que o formato institucional do MESP deveria ser compatível com o projeto político do governo do período. Fonseca (2010) aponta que, nos primeiros anos do ministério, este era caracterizado pela indefinição de propostas e projetos, o que era perceptível na alternância de ministros. Em 1934, tem-se a entrada de Gustavo Capanema, que possibilitou mudanças e principalmente a implementação de reformas. Compreende-se que, quando o MESP foi criado, este órgão atuaria como um instrumento burocrático que tinha como desígnio consolidar uma estrutura de serviços em todo o país. E esta estratégia, de reforçar a referida organização burocrática e a forma com que pretendia atuar 
(nacionalmente), não só se ajustava aos “interesses políticos do governo federal em sua relação com os governos estaduais, como também atendia aos objetivos delineados na esfera ideológica, voltados para a consolidação de uma nova nação” (FONSECA, 2010, p. 138).

Getúlio Vargas pretendia que o Brasil fosse um país moderno. Pensando nessa linha, o Estado deu novo rumo no que se refere às campanhas contra a tuberculose, oferecendo suporte econômico aos Congressos Nacionais de tuberculose. Outra ação do governo foi o pedido de elaboração de um plano nacional, centralizador de combate à tuberculose. Este projeto foi aprovado por Getúlio Vargas, mas nunca chegou a ser colocado totalmente em prática. Situações como esta mostram, segundo Bertolli Filho (2001, p. 71) que "apesar dos pronunciamentos oficiais que prometiam assistência aos doentes do peito, $\mathrm{o}$ Estado getulista hesitava em liberar verbas para o combate à Peste Branca e para o socorro das vítimas desta enfermidade”.

A ampliação da estrutura administrativa da saúde dava a oportunidade para o governo expandir a sua vigilância sobre a sociedade. Com isso, cabia a cada Estado cuidar das condições sanitárias, bem como intervir em casos epidêmicos e desenvolver campanhas educativas em relação à prevenção de doenças. Entretanto as verbas federais destinadas à higiene sempre foram poucas, visto que cabia aos Estados a responsabilidade para criar fundos para o atendimento dos enfermos pobres. Pela falta de uma política mais voltada para o combate à tuberculose, observa-se que, até o ano de 1936, havia poucas entidades direcionadas aos tuberculosos. Segundo Bertolli Filho (2001, p. 70):

O estado de São Paulo concentrava o maior número de unidades de saúde, contando com 14 sanatórios e hospitais-sanatórios, sendo seguido por Minas Gerais com três sanatórios, o estado do Rio de Janeiro com dois nosocômios e o Paraná com apenas uma casa de saúde especializada.

No Paraná a casa é o Sanatório São Sebastião da Lapa, o único que tratava de doentes do peito. Os tratamentos que giravam em torno dos tuberculosos envolviam a higiene, o clima e as práticas de curandeirismo em Guarapuava. ${ }^{1}$ Não será dado destaque, neste artigo, ao último item mencionado.

Percebe-se que, no período da Primeira República, existe o movimento pela reforma da saúde, na qual observou-se uma "crescente, identificação, pela sociedade brasileira,

\footnotetext{
${ }^{1}$ Cf. OLIVEIRA, Leonara Forquim de Mattos. Todos são curandeiros: saberes populares e curandeirismo nos processos crime de Guarapuava. Trabalho de Conclusão de Curso, Licenciatura em História, Guarapuava, UNICENTRO, 2008. A autora comenta que mesmo com a mudança na Legislação (código Penal Republicano de 1890), atuação dos curandeiros ainda era permitida em Guarapuava, que perpassará o século XIX, até meados do XX.
} 
dos problemas sanitários como problemas de interdependência” (HOCHMAN, 2006, p. 61). Com isso, tem-se uma maior consciência pública sobre a responsabilidade governamental em saúde, com as atenções voltadas para o saneamento no interior do país. Como apontaram Bertolli Filho (2001) e Hochman (2006), houve a necessidade de publicizar as questões referentes à saúde. Já com a criação do MESP (1930), tem-se uma maior dinamização dos projetos, principalmente, dos relacionados aos tuberculosos. No governo de Vargas, nota-se que a gestão de Gustavo Capanema estava preocupada com o fato de que o governo deveria marcar presença em todo país, capitais, no interior e nos municípios para articular bem a questão de serviços de saúde. Com isso, há "desenvolvimento de ações efetivas e bem-sucedidas, eram necessários representantes do governo federal nos estados e o estabelecimento de parcerias com os governos locais" (FONSECA, 2010, p. 139).

\section{Entre o clima e a Higienização: Análise de Discurso dos Relatórios do Hospital} São Vicente de Paulo

$\mathrm{Na}$ terceira parte, observa-se a análise dos documentos por meio do Modelo Tridimensional. Este modelo é proposto na Análise de Discurso Crítica que tem como finalidade o debate teórico e metodológico do discurso no tratamento da linguagem como prática social. Para Magalhães (2005, p. 3), “A ADC estuda textos e eventos em diversas práticas sociais, propondo uma teoria e um método para descrever, interpretar e explicar a linguagem no contexto sociohistórico." Este trato com a linguagem nos mostra que a ADC possui um campo de interação entre a Linguística e a Ciência Social, pois o discurso é compreendido como reflexo da prática social. Nessa perspectiva Resende e Ramalho (2004, p. 186) explanam que o discurso é socialmente constitutivo "através do discurso se constituem estruturas sociais - e constituído socialmente - os discursos variam segundo os domínios sociais em que são gerados, de acordo com as ordens de discurso a que se filiam".

A $\mathrm{ADC}$ que podemos observar no livro - Discurso e mudança social -, de Norman Fairclough (2001), busca a relação entre o elemento linguísitico com o social. Compreende-se que o discurso contribui para a "constituição de todas as dimensões da estrutura social que, direta ou indiretamente, moldam e restringem suas próprias normas e convenções, como também relações, identidades e instituições que lhe são subjacentes” (FAIRCLOUGH, 2001, p. 91). Este campo de análise procura apresentar como as práticas discursivas estão conectadas com as estruturas sociopolíticas mais amplas, de dominação 
e poder e também como o fenômeno discursivo é visto como um texto que nos mostra práticas discursivas e práticas sociais. A primeira dimensão do modelo Tridimensional de análise proposto por Fairclough (2001) é a análise textual. Esta se utiliza dos princípios teóricos da Linguística Sistêmica Funcional de Halliday, a qual Fairclough (2001, p. 2005 ) comenta que o teórico "faz uma apresentação mais avançada de uma forma de gramática particularmente útil à análise de discurso". Por meio de textos, podemos perceber as estruturas da sociedade no que tange a ideologias, a dominação etc. Neste sentido, é significativo, para a análise no campo da ADC, utilizar a Gramática Sistêmico Funcional (GSF). Essa união expõe a conexão entre texto e contexto como sinaliza (HALLIDAY, 1994, p. xiii apud Schelee et. al, 2012, p. 2027) “uma gramática funcional é essencialmente uma gramática 'natural', no sentido de que tudo nela pode ser explicado, em última instância, com referência a como a língua é usada." Na concepção sistêmico-funcional, a forma subjaz à função. Isso significa explanar que a linguagem é concebida em seu vínculo com a estrutura social. Schelee et al. (2012, p.2027) aponta que:

\begin{abstract}
O estudo da gramática implica a consideração do discurso como dado primário e a estrutura da gramática torna-se indissociável da estrutura do discurso. Parte-se, assim, do pressuposto de que gramática e interação social se complementam: a gramática é um recurso responsável pela interação social e, ao mesmo tempo, está sujeita à interação, uma vez que é no processo de interação social que se dá a aquisição, a manutenção e a mudança da linguagem.
\end{abstract}

Percebe-se que a linguagem faz parte do processo social, mas também se constitui como expressão. Isto porque ela está organizada de uma maneira que permite fazer uma relação com o social. Nesse sentido, busca-se a composição interna da linguagem em termos das funções

No que tange à prática discursiva, compreende-se que abrange "processos de produção, distribuição e consumo textual, e a natureza desses processos varia entre diferentes tipos de discurso de acordo com fatores sociais" (FAIRCLOUGH, 2001, p. 107). Com relação à dimensão que envolve o discurso como prática social, relaciona-se com aspectos ideológicos e hegemônicos no discurso. É importante frisar que as duas últimas dimensões não são contrárias como afirma Fairclough (2001, p. 99). Segundo o autor, "pratica discursiva aqui não se opõe a prática social: a primeira é uma forma particular da última.”

A ADC analisa as interações sociais através de textos. $\mathrm{O}$ eixo de sua pesquisa científica é a mudança social por meio da mudança discursiva, sendo que uma está relacionado a outra. Fairclough (2001) emprega o termo discurso no sentido que o uso da linguagem 
ocorre na prática social, ou seja, o social e o discurso se constituem mutuamente. $\mathrm{O}$ analista crítico do discurso, ao observar a linguagem como prática social, revela a produção, a conservação e a sua transformação.

\subsection{Análise textual: A linguagem como espelho do Hospital São Vicente de Paulo}

A análise textual proposta por Norman Fairclough parte das categorias sistematizadas por Halliday em sua Gramática Sistêmico Funcional (GSF). ${ }^{2}$ A análise desta dimensão por meio da GSF contribui para compreender a dinâmica da linguagem, as funções que a linguagem exerce em textos. O nosso sistema linguístico nos permite várias possibilidades de escolhas, essas são combinadas à medida que almejamos alcançar algo em determinado contexto.

O documento histórico possui 42 páginas e, como foi exposto, o foco do artigo são os doentes do peito. Desta forma, a seguir, são transcritos trechos que possibilitam refletir os discursos que permeiam o respectivo período. A análise textual contempla as variáveis do contexto de situação (campo, relações e modo) que se relacionam com as metafunções (ideacional, interpessoal e textual).

(1) O município de Guarapuava com seus 80.000 habitantes, deveria possuir assim 400 leitos, acontece entretanto que o modesto Hospital São Vicente de Paulo de Guarapuava, com seus 20 leitos, se vê cada vez mais endividado, sem os necessários recursos [...]. Esta deficiência de recursos materiaes, já há anos não nos permite apresentar ao povo guarapuavano as informações detalhadas sobre a vida e a atividade dessa Casa de Caridade. Fizemos isso agora concientes de nossa obrigação de dar contas ao dono supremo - ao povo - certos também que os nossos concidadãos tomando o conhecimento dos trabalhos já realisados e a realisar, procuração por todos os meios auxiliar-nos na nossa tarefa. (p. 17, sic).

(2) O grande problema da tuberculose que há alguns anos está na ordem do dia em Guarapuava, não poude deixar indiferente o serviço medico do Hospital com lesões suspeitas de tuberculose, alem dos conselhos higienicos dietéticos e medicações apropriadas, foi ministrado também o tratamento por meio do antigeno anti-tuberculoso, produsido e recomendado pelo Instituto Pasteur de Paris. Como se sabe, todo o problema da tuberculose está no diagnostico e no tratamento precoce desta moléstia, que Grancher com todo o acerto considerava como a mais curável das moléstias crônicas. Infelizmente, poucos são os

\footnotetext{
${ }^{2}$ Cf. FUZER, Cristiane; CABRAL, Sara Regina Scotta. Introdução à gramática sistêmico funcional em Língua Portuguesa. 1. ed. Campinas, SP: Mercado de Letras, 2014.
} 
doentes que procuram o médico na fase inicial das moléstia, preferindo recorrer as mesinhas aos remédios caseiros, homoepaticos ou xaropes multicolores, etc. (p. 20, sic).

(3) [...] O internamento de tuberculosos no Hospital encontra sempre as mesmas dificuldades que nos anos anteriores; pois a ausência de uma enfermaria especial, não permite o isolamento completo desses contagiosos. A construção de um pavilhão especial para o isolamento dos tuberculosos, è um dos problemas que tem de ser resolvido o mais brevemente possível. (p. 20, sic).

(4) O grupo das moléstias infecciosas é bem pouco numeroso: 3 casos de sarampo, 3 de para tifo, 4 de angina diftérica e crupe, 1 de varíola e 3 de menengite; este numero diminuto das moléstias infecciosas, corresponde perfeitamente ao exelente estado sanitário do Municipio, onde quase não existem as moléstias infecciosas agudas. Infelizmente não se pode fazer esta constatação optimista a respeito da tuberculose, que cada vez mais alastra-se na cidade e penetra já no interior do Municipio. (p. 24, sic).

(5) Durante os 6 ultimos anos foram internados 47 tuberculosos, e só em 1932 foram atendidos no ambulatório 22 doentes. (mapa numero 6). Urge pois, tomar as medidas mais enérgicas do combate a esse flagelo. Entre as medidas a tomar em primeiro lugar, deve ser colocada a propaganda intensiva anti-tuberculosa, com exposição de cartazes, filmes projeções luminosas, realisação das conferencias, distribuição de folhetos. O hospital já iniciou estes serviços a medida de suas possibilidades. A desinfeção das casas onde permaneciam os tísicos, a organisação de um pavilhão especial para tuberculosos no Hospital, o maior desenvolvimento possível do ambulatório são medidas ao alcance dos poderes públicos locaes e do povo de Guarapuava. (p. 24, sic).

(6) A nosso pedido, $\mathrm{o}<<$ Comitè Nacional de Defensa contre La tuberculose $>>$ na França, mandou 24 diferentes cartazes sugestivos e muito bem impressos. $\mathrm{O}$ Departamento de Saude Pública do Rio , mandou também 5 cartazes de propaganda contra tuberculose e grande numero de folhetos explicativos sobre varias molestias infeciosas: (tuberculose, molestias venéreas, meningite, tifo, varíola, etc) 5 cartazes foram entregues ao Diretor do Grupo Escolar , 4 reservados para o Hospital e os 20 restantes distribuídos pelos pontos da cidade mais frequentados (clubes operários, barbearias, cafés, etc). Esta propaganda devia ser desenvolvida em muito maior escala, com focalisação de projeções luminosas e 
filmes, porem como sempre, a falta de recursos não permite fazer a aquisição do material necessário. (p. 33, sic).

O contexto de situação-campo pode ser descrito da seguinte forma: refere-se ao relatório do Hospital São Vicente de Paulo entre as décadas de 1927 a 1932. A finalidade da construção desse documento é a prestação de contas à sociedade. O objetivo é conscientizar os cidadãos dos trabalhos realizados por esta instituição. As variáveis de relações envolvem os participantes na situação que são o diretor clínico Dr. Miguel Bohomoletz que produziu os relatórios e a Tipografia Pimpão. Temos também os participantes do texto que são a comunidade guarapuavana. A relação de modo diz respeito ao tipo de via de comunicação que, neste caso, se dá por meio da linguagem verbal, modo de organização expositivo. $\mathrm{O}$ texto divide espaço com outras questões como o abastecimento de água, cirurgias, despesas, arrecadação em festas e até mesmo com a preocupação com outras doenças (lepra, sífilis etc.).

A metafunção ideacional remete-se às experiências do mundo expressas pelos indivíduos. O estudo passa a analisar os aspectos léxico-gramaticais. "A parte da gramática em que se manifestam os significados experienciais é o sistema de transitividade" (FUZER; CABRAL, 2014, p. 39). Especialmente no trecho (1) podemos observar a representação que o corpo médico deseja passar para a sociedade guarapuavana. Em todo o relatório, os esforços que cotidianamente realizam são demonstrados, bem como a relevância de contribuir para o crescimento da instituição. Neste caso, tem-se a representação da experiência interna que reporta aos processos mentais.

A transitividade é um sistema de oração que afeta o verbo como também os participantes e as circunstâncias. Há vários tipos de processos e, dependendo da escolha, os participantes possuem denominações diferenciadas. No caso do processo mental, os participantes são denominados Experienciador e Fenômeno. As circunstâncias ligam-se aos processos transmitindo a localização dos eventos no tempo, no espaço, no modo ou a causa. No trecho (1), temos como exemplo para o termo que indica o Experienciador Fizemos. Em seguida, observamos uma locução prepositiva - isso agora, que nos indica a circunstância. E o fenômeno é referido em conscientes de nossa obrigação.

A linguagem proporciona uma interação entre os indivíduos no meio social. Os aspectos léxico-gramaticais estudados a partir daqui ocorrem na metafunção interpessoal da linguagem que é demonstrado pelo sistema de Modo. No trecho (2), percebem-se elementos os quais permitem que o leitor compreenda a gravidade da doença e informam que, no Hospital, é possível inteirar-se mais sobre os tipos de tratamento. Esta interação 
entre escritor/leitor chama-se troca de bens e serviços, e ocorre quando o indivíduo utiliza a linguagem para induzir o comportamento de alguém.

Outro valor trocado na interação entre os indivíduos, troca de informação, é perceptível na passagem (3), a qual apresenta informações das dificuldades que estão enfrentadas nos últimos seis anos. Assim como no trecho (4), que expõe informações acerca das moléstias que o Município enfrenta, a preocupação gira em torno da tuberculose que avança pelo interior da cidade, quando se utiliza "infelizmente", "cada vez mais" tem-se a intenção de demonstrar ao leitor a gravidade do não tratamento da doença. Nos excertos (5) e (6), observa-se a troca de bens e serviços. Este demonstrando a interação entre o Hospital São Vicente, o Comitê Nacional de Defensa contra a tuberculose na França e o Departamento de Saúde Pública do Rio de Janeiro, ao fazerem pedidos de encomendas de propagandas. Nesses trechos, mostra-se a potencialidade das propagandas que tomem o conhecimento da importância deste mecanismo em uma cidade que está com dificuldades de conter a tuberculose por falta de recursos. Aquele por sua vez traz a estatística de doentes do peito internados. Entre as medidas realizadas, aponta a desinfecção das casas. Esse trecho torna-se uma troca de informação porque deseja que as autoridades diante do relato tomem providências.

E por fim, a metafunção textual que realiza a variável contextual modo. Este sistema organiza os significados experienciais e interpessoais em um todo. Nesta metafunção a oração é vista como mensagem. Sendo assim, a análise se dá pela estrutura temática. $\mathrm{Na}$ GSF, existem dois sistemas que envolvem a organização da mensagem em um texto. $\mathrm{O}$ primeiro é a Estrutura de informação que "envolve os componentes que são denominados informação dada e informação nova (nível do conteúdo). O segundo é chamado Estrutura temática e envolve as funções denominadas Tema e Rema (nível da oração)” (FUZER; CABRAL, 2014, p. 128).

$\mathrm{Na}$ Estrutura de informação, os elementos são relacionados entre o que é dado e o que é novo. No (1), temos o dado, que é a informação acerca da estrutura do hospital e a falta de recursos. Isto é retomado com o referente "Esta". Este elemento novo é o compromisso assumido pelo Hospital de prestar contas ao povo.

No parágrafo (2), podemos observar que: o dado é "o grande problema da tuberculose", e o restante da oração (que há alguns...) é o novo. O termo "serviço" torna-se um elemento $d a d o$, haja vista iniciar a informação sobre as medidas que a equipe faz, e os seguintes são os elementos novos os quais são retomados pelas palavras "além" e "também". Já o termo "Como se sabe" retoma todo o conhecimento acerca do tratamento. "O internamento", no trecho (3), é o elemento dado e o restante é o elemento novo. 
No (4), temos como elemento dado "O grupo das moléstias infecciosas", e o novo é o que explica quais são essas moléstias (três casos de sarampo...). Com o termo "infelizmente", a informação torna-se velha e passa a trazer um dado a mais que se refere à tuberculose a qual agregam novas informações. Já no (5), temos um elemento novo que é o número de internados por tuberculose. No período seguinte, aparece um elemento dado "tomar medidas". Em seguida, é explanado quais são as medidas em "Entre as medidas a tomar em primeiro..." que retoma o dado.

Com relação à Estrutura Temática, percebe-se que o relatório do Hospital São Vicente de Paulo, como foi dito, abarca várias questões. A sua estrutura é fracionada em tópicos como, por exemplo: cirurgias; higiene; serviços prestados; saneamento etc. Como foi observado nos trechos selecionados, nota-se que a dificuldade a qual o Hospital enfrenta é sempre retomada. No que tange à tuberculose, os trechos apresentam a preocupação em relação ao alastramento da doença, ao número de mortes pela enfermidade, à questão do tratamento e às propagandas ocorridas durante os anos do respectivo relatório. De forma geral, o tema que perpassa o relatório são os serviços prestados à sociedade guarapuavana, e o rema são os tipos de serviços que foram prestados e as necessidades que o Hospital possui para manter o bom funcionamento destes serviços.

\subsection{Análise discursiva e social: "a tuberculose na pauta do dia"}

Por meio da historiografia, conseguimos tecer um panorama acerca da representação do tuberculoso ao longo da história e as suas modificações. Compreender essa questão torna-se importante pois contribui para entender como esses indivíduos eram percebidos pela sociedade.

Os românticos (século XIX) se utilizavam da tuberculose como um recurso para negar o desencanto da vida social, tanto que a doença passou a ser concebida como enobrecedora. Segundo Bertolli Filho (2001, p. 45), "definida como 'febre das almas sensíveis', a consunção foi abraçada pelos textos literários como argumento exaltador dos dotes de uma larga parcela da elite intelectual”.

Sendo assim, a tuberculose era considerada uma constatação da sensibilidade e da genialidade que coordenava a composição dos escritos românticos. Ausentes do ambiente de pobreza, os poetas e escritores românticos conferiram à tuberculose o mágico poder de redefinição positiva da vida. A genialidade era explicada pelo avanço da tuberculose, visto que, à medida que a doença expandia, produzia boas ideias no trabalho intelectual.

Desde o ciclo revolucionário de 1848, houve uma revisão da imagem do tísico que, 
segundo Bertolli Filho (2001, p. 48) "mantendo-se fiel aos clichês explorados pelo romantismo, passou a exibir esquemas condenadores da trajetória de vida e dos comportamentos atribuídos aos afetados do peito”. Nesta perspectiva da mudança de concepção em relação à tuberculose, Soares (1994, p. 127) comenta que,

A tuberculose, no século passado, foi uma doença da paixão, ceifando a vida de literatos, poetas, músicos, filósofos e mundanas célebres. Na virada do século XX, passou a ser considerada um mal social e sua ocorrência encontra-se, desde então, associada às condições de vida.

A mudança que ocorre do século XIX para o XX não é somente da concepção da doença, mas especialmente das práticas acerca do tratamento. E com isso compreendemos os debates que ocorreram no século XX sobre a profilaxia. Desta forma, o foco é o século XX. Com isso, devemos recordar alguns pontos importantes feitos até aqui e que passarão a serem discutidos mais detalhadamente e, especialmente, no contexto guarapuavano: a questão do clima, a da intervenção do Estado em políticas de saúde e a da higiene.

Percebem-se novos posicionamentos sociais e sanitários, sendo que, naquele período, foi deixada de lado a ideia de que tuberculose era marca da camada culta, passando a ser uma enfermidade da população pobre. Segundo Guerrad (p. 189, s/d), "se o 'doente do peito, romântico do início do século, apresentava aspectos de que o gênio parecia tirar partido [...], o proletário portador de germes revela-se, ele, um perigo público." Sendo assim, a tuberculose, em meados do século XIX, é associada à miséria, como também comenta, Sontag (1984, p. 21), “a tuberculose é sempre imaginada como uma doença da pobreza e da privação - falta de roupas, corpos magros, quartos sem aquecimento, higiene deficiente, alimentação inadequada.”

Observa-se que a medicina pública buscou delimitar a tuberculose no conjunto de moléstias sociais, "os higienistas compuseram novas estratégias de intervenção no cotidiano coletivo, sem no entanto abandonar os pressupostos fantasiosos que pairavam sobre o comportamento infectado" (BERTOLLI FILHO, 2001, p. 49).

A questão do clima, já aparecia no final do século XVIII. Os clínicos passaram a reiterar a necessidade de viajar, para a recuperação da saúde. As peregrinações feitas pelos doentes do peito, nos lugares recomendados pelos médicos, segundo Bertolli Filho (2001, p. 55), "fomentou o repúdio aos doentes com os pulmões corroídos, tornando os locais de cura pioneiros na elaboração de códigos sanitários que limitavam a liberdade dos contaminados". 
A partir do momento em que conseguiram definir o agente responsável pela tuberculose, a Higiene pública começa perceber que a moléstia poderia ser, no mínimo, controlada. Desta maneira, podemos perceber que, desde o final do século XIX, segundo Bertolli Filho (2001, p. 39), "ganharam maior consistência as regras sanitárias que cobravam a desinfecção dos objetos pessoais e do catarro dos enfermos, desdobrando-se na ostensiva vigilância das pessoas e dos animais fimatosos”. A partir deste momento, percebe-se que somente quando a doença passa a ser contagiosa é que se torna a ser uma questão de saúde pública.

O século XIX, para Elias e Vianna, “tornou-se 'motivo de exílio': clima e isolamento sanatorial se revestiram de lógica terapêutica e diferentes paisagens, identificadas pela 'rejeição da cidade', foram convertidas em locais de cura” (ELIAS; VIANNA, 2007, p. 1296). Com isso, nota-se que a metade do século XIX, foi propícia para a marginalização do doente do peito, sendo o isolamento sanatorial o último recurso dos enfermos. Para Sontag (1984, p. 50), “a tuberculose era apavorante não só por ser contagiosa, como a cólera, mas por que a consideravam uma 'desgraça' aparentemente arbitrária e inexprimível”, afinal a representação do doente do peito vinha sendo modificada: uma doença atribuída à elite agora era também uma doença dos pobres

Com relação ao Estado do Paraná, nota-se que, mesmo com as diferenças regionais, a questão do clima estava na pauta dos discursos das autoridades políticas e dos médicos paranaenses (final do séc. XIX e início do séc. XX). Por um certo tempo, segundo Larocca e Marques (2010, p. 154) "o clima excelente foi considerado o principal agente de saúde pública no Paraná provincial”. Considerava-se que a altitude e o clima do Estado contribuíam para a cura dos tísicos, mas esta concepção, de que o clima era uma ótima opção para o tratamento, foi colocada em xeque já que não se poderia atribuir somente ao clima a diminuição do índice de mortes por doenças. A partir da década de 1920 (séc. XX), o número de casas hospitalares foi expandido, sendo que,

Munhoz da Rocha faz uma política de saúde pública monumental, simbolizada pela construção de três grandes instituições hospitalares: uma para a centralização de todos os leprosos do estado, o Leprosário São Roque; outra para atendimento aos tuberculosos, o Sanatório São Sebastião da Lapa e, finalmente, uma para doenças transmissíveis em geral, o Hospital de Isolamento Oswaldo Cruz (OLINTO, 2002, p. 155).

A respeito do discurso de que o clima traria algum benefício ou até mesmo a cura para os tuberculosos, Ribeiro (1929, p. 65) comenta que "Guarapuava possui o clima 
suave das zonas temperadas". Porém, a cidade de Guarapuava, neste período (1930), tinha alguns problemas em relação à higiene pública. Ribeiro (1929, p. 69, sic) expressa algumas percepções sobre a cidade: "Guarapuava-cidade em más condições de instalação e Guarapuava-clima com apreciaveis vantagens sobre logares frequentemente recomendados para estação climaterica.”

Como vimos São Paulo era o estado que possuía mais casas para o atendimento aos tuberculosos. Poucos estados apresentavam leitos hospitalares que fossem de exclusividade dos enfermos do peito. No Relatório do Hospital São Vicente de Paulo, na cidade de Guarapuava/PR, observa-se a falta de leitos, bem como a preocupação com os tuberculosos e, consequentemente, com o aumento dos infectados. Por isso a preocupação de criar o mais breve possível o pavilhão para os tuberculosos. Diante do número das mortes por tuberculose, era necessário, como aponta o próprio relatório do Hospital, construir um espaço somente para esses doentes. Mesmo com poucos recursos disponíveis, os médicos de Guarapuava consideravam que o doente do peito estaria melhor no hospital do que em casa, pois, em casa, o enfermo não teria condições higiênicas adequadas para o tratamento:

O Hospital, dispõe somente de duas enfermarias e de dois quartos particulares; da exposição anterior, podiamos ver que os dois quartos particulares se tornaram insuficientes. Mas muito mais grave é a ausencia das salas ou pavilhões para o isolamento dos doentes infeciosos. [...]. Todos esses 63 doentes, necessitavam do isolamento o mais rigoroso possível. Entretanto o serviço medico do Hospital encontra-se deante deste dilema: ou deixar o doente contagioso disseminar a infecção na casa de sua família e dos vizinhos, ou interna-lo no Hospital em condições higienicas incomparavelmente melhores (Relatório do Hospital São Vicente de Paulo - 1927-1932).

O relatório do Hospital São Vicente de Paulo (1927-1932), compara a estrutura do Hospital com a casa dos pacientes. As condições higiênicas da casa do doente não eram propícias para o seu tratamento. Eurico Branco Ribeiro comenta que 50\% das casas são de madeira em Guarapuava (1929, p. 50). Esta preocupação dos médicos é plausível, pois, "Guarapuava não possui exgotos, nem agua encanada, nem serviço de limpeza publica” [sic]) (RIBEIRO, 1929, p.46).

Em nível nacional, como apontou a historiografia ${ }^{3}$, a tuberculose era uma das do-

\footnotetext{
${ }^{3}$ Ver: BERTOLLI FILHO, Claúdio. História Social da Tuberculose e do Tuberculoso: 1950-1950. Rio de Janeiro, Editora Fiocruz, 2001. FONSECA, Cristina M. Oliveira. Saúde Pública no governo Vargas. In: PONTE, Carlos Fidelis; FALLEIROS, Ialê. Na corda bamba de sombrinha: a saúde no fio da história. Rio de Janeiro: Fiocruz/COC; Fiocruz/EPSJV, 2010. GUERRAND, R. Guerra a tuberculose. In: LE, GOFF, J. As doenças têm histórias. Lisboa: Terramar, s/d. ANTUNES, J. L. F. et al. A tuberculose através do século: ícones canônicos e signos do combate à enfermidade. Ciência \& Saúde Coletiva, 5 (2):367-379, 2000
} 
enças que mais causava morte. Sendo assim, percebe-se que em Guarapuava, a doença causou um número razoável de mortes, apesar das campanhas, fato que preocupava os médicos. Este quadro é explanado no seguinte trecho do relatório (1927-1932, p.24): “O grupo das moléstias infecciosas é bem pouco numeroso: [...]. Infelizmente não se pode fazer esta constatação optimista a respeito da tuberculose, que cada vez mais alastra-se na cidade e penetra já no interior do Município”. Neste trecho, pode-se observar que, diferente de outras doenças infecciosas, a tuberculose se espalhava cada vez mais no interior do município, e que Hospital São Vicente de Paulo tem poucos recursos para combater a moléstia.

A administração varguista mostrou-se interessada em fazer um projeto federal para assistência aos doentes pobres, visto que é direcionado à questão de normalizar o tecido social, bem como a intenção de intervir na saúde popular que está relacionado como preparação para o lançamento da Campanha para a ocupação de áreas do interior do Brasil. Sendo assim o órgão da Saúde Pública ficou encarregado de possibilitar migrantes saudáveis para o projeto governamental intitulado 'Marcha para Oeste'. Compreende-se que a política do governo de Getúlio não se concretizou na prática, apesar de terem sido aprovados vários projetos, inclusive o de combate à tuberculose, ou seja, não se vê no período uma efetivação dos projetos na sociedade.

Sendo assim, na Primeira República, as Ligas e Estado conduziram uma política de controle da moléstia que vai servir como modelo para os outros estados. Porém, os poderes públicos serão cobrados cada vez mais para a questão do combate à tuberculose. Observa-se que, com a entrada de Getúlio Vargas na direção do governo federal, seus projetos eram voltados no sentido de centralização e na intervenção governamental na sociedade. Com a ampliação da estrutura administrativa da saúde, coube ao estado cuidar das condições sanitárias, bem como desenvolver ações educativas em relação a prevenção das doenças. Apesar disso, não havia uma política que tivesse como foco o combate à tísica, como também eram poucas entidades que tratavam da doença do peito. No Paraná, como foi apontado anteriormente, na década de 1920, tem-se a sistematização das instituições de saúde no estado, sendo criado o Sanatório São Sebastião da Lapa, para o atendimento dos tuberculosos.

É dentro deste contexto que o município de Guarapuava se encontrava. Podemos constatar que Hospital São Vicente de Paulo não obtinha recursos suficientes, bem como não conseguia atender todas as pessoas que se encontravam com a moléstia do peito. 


\section{Considerações Finais}

A tuberculose estava 'na ordem do dia' nos discursos médicos, das autoridades políticas e principalmente no interior do Estado do Paraná que notavelmente não possuía tantos recursos para o combate à doença. Como foi apontado, o governo da Primeira República se preocupou com a questão da saúde pública e, mesmo com aprovação de lei ou a criação das Ligas Paulistas, há uma ausência do poder público na luta contra a doença. É perceptível a atuação das Ligas Paulistas no combate à tuberculose, na qual influenciaram na questão de cartazes e publicização acerca do tratamento que serviram como modelo aos demais estados. Neste mesmo período, no Paraná, tem-se a criação do Sanatório São Sebastião da Lapa, que auxiliava no tratamento e combate da doença no Estado.

Já o período que se refere a esta pesquisa, podemos perceber que há uma maior preocupação acerca da doença e uma centralização referente à saúde pública, mas os projetos não tiveram uma amplitude, assim como o combate à doença. A Análise Crítica do Discurso possibilitou evidenciar, por meio dos relatórios do Hospital São Vicente de Paulo em Guarapuava, que a doença estava na pauta de preocupação da cidade, principalmente porque o Hospital não tinha leitos suficientes e um ambiente para o isolamento dos tuberculosos. Entre as formas de tratamento que ainda eram utilizadas, constatamos que a climatoterapia era vigente no período, visto que o Paraná era considerado um estado propício para o tratamento, devido ao seu clima agradável. Já na cidade de Guarapuava, no livro de Eurico Branco Ribeiro Coração do Paraná, podemos perceber a ambiguidade que existia na cidade entre a higiene e o clima. Ribeiro aponta que é um bom lugar por causa de seu clima, o que contribuiria para o tratamento dos doentes. Porém a cidade se encontrava em péssimas condições higiênicas. Sendo assim, através do modelo teórico de Análise do Discurso e da Historiografia, constatamos que a climatoterapia passa a ser colocada em xeque, e a ênfase se dá na questão do isolamento dos doentes e da higienização.

Com a entrada de Getúlio Vargas na direção do governo federal, observa-se que os projetos eram voltados para a centralização e a intervenção governamental na sociedade. Com a ampliação da estrutura administrativa da saúde, coube ao Estado cuidar das condições sanitárias, bem como desenvolver ações educativas em relação à prevenção das doenças. Apesar disso, não havia uma política que tinha como foco o combate à tísica, como também eram poucas entidades que tratavam da doença do peito. Nos relatórios não houve menção de ajuda por parte do governo Federal em relação às problemáticas com as doenças infecciosas. 


\section{Referências}

ANTUNES, J. L. F. et al. A tuberculose através do século: ícones canônicos e signos do combate à enfermidade. Ciência \& Saúde Coletiva, v. 5, n. 2, p. 367-379, 2000.

BERTOLLI FILHO, C. História Social da Tuberculose e do Tuberculoso: 1900-1950. Rio de Janeiro, Editora Fiocruz, 2001.

FONSECA, C. M. O. Saúde Pública no governo Vargas. In: PONTE, C. F.; FALLEIROS, I. (Org.). Na corda bamba de sombrinha: a saúde no fio da história. Rio de Janeiro: Fiocruz/ COC; Fiocruz/EPSJV, 2010.

GUERRAND, R. Guerra a tuberculose. In: LE, GOFF, J. As doenças têm histórias. Lisboa: Terramar, s/d.

LAROCCA, L. M.; BELTRÃO MARQUES, V. R. A construção do novo Paraná: uma análise dos discursos higienistas (1853-1930). Cogitare Enferm, v. 15, n. 1, p. 153-157, jan. / mar., 2010.

LENHARO, A. Sacralização da Política. 2. ed. Campinas, SP: Papirus, 1986.

MAGALHÃES, I. Introdução: A Análise de Discurso Crítica. D.E.L.T.A., v. 21, n. espec., p. 1-9, 2005.

OLINTO, B. A. Pontes e Muralhas: Diferença, lepra e tragédia no Paraná. Guarapuava: UNICENTRO, 2007.

PAIVA, C. H. Assunção. Imperialismo \& filantropia: a experiência da Fundação Rockefeller e o sanitarismo no Brasil na Primeira República. História, Ciências, Saúde Manguinhos, Rio de Janeiro, v. 12, n. 1, p. 205-14, jan. / abr. 2005

PONTE, C. F.; FALLEIROS, I. Na corda bamba de sombrinha: a saúde no fio da história. Rio de Janeiro: Fiocruz/COC; Fiocruz/EPSJV, 2010.

RELATÓRIOS, Hospital São Vicente de Paulo. (1926-1927 e 1927-1932). Arquivo Histórico Municipal de Guarapuava.

RESENDE, V. M.; RAMALHO, V. C. V. S. Análise de Discurso Crítica, do Modelo tridimensional à articulação entre práticas: implicações teórico-metodológicas. Linguagem em (Dis)curso - LemD, Tubarão, v. 5, n. 1, p. 185-207, jul./dez. 2004

RIBEIRO, E. B. Coração do Paraná (Estudo Sanitário). Guarapuava, 1929.

SCHELEE, M. B. et. al. Uma breve introdução à Linguística sistêmico-funcional. In: SCHELEE, M. B. et. al. A Linguística sistêmico-funcional no quadro das grandes teorias lingüísticas: propostas de aplicação. Anais do XVI CNLF. Rio de Janeiro: CIFEFIL, 2012.

SIGOLO, R. P. Saúde em Frascos: Concepções de Saúde, Doença e Cura, 1930/1945. 1995. 330 p. Dissertação. Universidade Federal do Paraná. Curitiba, 1995.

SOARES, P. P. A dama branca e suas faces: a representação iconografia da tuberculose. História, Ciências, Saúde - Manguinhos. v. I, n. 1, p. 127-134, jul. / out., 1994. 
SONTAG, S. Doença como metáfora. Rio de Janeiro: Graal, 1984.

VIANNA, P. V. C.; ELIAS, P. E. M. Cidade Sanatorial, Cidade industrial: espaço urbano e política de saúde em São José dos Campos, São Paulo, Brasil. Cad. Saúde Pública, Rio de Janeiro, v. 23, n. 6, p. 1295-1308, jun. 2007.

Submetido em: 26/02/2017

Aceito em: 25/04/2017 